\title{
Integrating Herzberg and Social Exchange Theories to Underpinned Human Resource Practices, Leadership Style and Employee Retention in Health Sector
}

\author{
Mohammad Fathi Almaaitah \\ School of Business Innovation and Technoprenuership \\ Universiti Malaysia Perlis, Malaysia \\ E-mail: mmaaitah1987@gmail.com \\ Yoshifumi Harada \\ School of Business Innovation and Technoprenuership \\ Universiti Malaysia Perlis, Malaysia
}

\begin{abstract}
M. F. Sakdan
School of Human Development and Technocommunication

Universiti Malaysia Perlis, Malaysia

Ayman Mahmoud Almaaitah

School of Business Administration

Mutah University, Jordan
\end{abstract}

Received: March 6, 2017

Accepted: April 15, 2017

Published: April 20, 2017

doi:10.5296/wjbm.v3i1.10880

URL: http://dx.doi.org/10.5296/wjbm.v3i1.10880

\begin{abstract}
The focus of this review study compliments the ongoing debate on the significance of employee retention in both private and public organizations. The contributions from scholars in retention study are enormous but there are still areas that need deep attention and further exploration. Most of the past studies on employee retention have mainly focus on its impact on outcomes such organizational commitment and organizational citizenship behavior. Thus,
\end{abstract}




\section{Macrothink}

to further reconfirm the importance of employee retention as a critical determinant of organizational effectiveness, it is essential to test its effect on a broader range of outcome variables. In this study, the role of human resources practices and leadership style are examined to see their effect on employee retention. While most of the extant literature used behavioral theories, this study combined Herzberg two factors (satisfier/motivator and dissatisfier/hygiene) and proposed a symbiotic relationship that could benefit both parties through social exchange theory. This study is limited in scope and context but the contribution to frontier of knowledge for both theory and practice is unparalleled. Health sector employee are limited in number due to duration of course of study and academic rigors involved, thus the limited numbers available are in competitive demand thereby encouraging high job mobility in this sector. Jordanian work force generally aspires to move to the West as ditto most developing countries. Using a well-defined HR practices coupled with leadership style will drastically reduce attrition rate and enhanced employee retention as conceptualized in this study. This will contribute to theory and practice through proactive measures that will not only discourage employee turnover but also enhance productivity.

Keywords: Employee retention, HRM practices, Leadership styles, Herzberg theory, SET 


\section{Introduction}

The world has witnessed a paradigm shift from human resource management (HRM) to human capital development (HCD) to underscore the importance of this phenomenon in an organization. The success of any organization is dependent on the quality and efficiency of its human resources (Mensah, 2014). No doubt, employees are regarded as life wire or key resources to sustain competitive advantage in an organization. The new paradigm consists of the knowledge, skills and abilities of the people employed in an organization which is indicative of their value (Armstrong, 2010). Therefore, organizations are duty bound to recruit and retain the most valuable, resourceful, efficient and productive workforce for optimal benefits. This is because turnover has a negative impact on organization especially on productivity, service and profitability (Tanwar, \& Prasad, 2016), In fact, the cost of replacing and hiring new employees is high and finding skilled employees can also be difficult (Kwenin, Muathe, \& Nzulwa, 2013).

Research has demonstrated that the quality of staff in an organization has a direct influence on organizational effectiveness. Demand and competition for highly qualified employees has increased, means recruiting and retaining talented employees is an ever-increasing challenge. These trends have engendered a more strategic approach to human capital development (Wilkin \& Nwoke, 2011). In view of market value and global job mobility across organizations, retention of high performing employees has become more challenging task for managers as this category of employees frequently move from one job to another. Theoretically, it has been accepted that a well-articulated human resource management practices usually reduce the turnover intention (Slattery \& Selvarajan, 2005). Similarly, employees are less likely to leave, rather stay longer with organizations when they perceive positive human resource practices such as job freedom, better opportunities, and better pay (Stewart \& Brown, 2009). The implementation of human resources policy is a function of leadership style in an organization. Therefore, HRM practices are associated with leadership of the top management in relation to employee retention. Leadership is significant to the survival and continues existence of an organization; the behavior of those entrusted with leadership can make or mar an organization. The prospect of an organization to a great extent depends on the leadership approach. Having identified leadership as one of the pillars needed to chart the future direction of the organization. The styles of the leaders at the top echelon do facilitate the zeal and commitment of followers to achieve the common goals when carrying out their duties (Thrush, 2012).

This study aimed to provide conceptual linkages among HRM and leadership style as applicable to public hospitals in Jordan. The study is underpinned by two factors Herzberg theory and social exchange theory to assess the relationship. Three main aspects of HR practices namely: compensation, career development and work-life balance were focused. The popular leadership factor in the study scope is transformational style was discussed in relation to the underpinning theories to establish the conceptual framework for this study.

\section{Global Employee Retention Scenario in Health Sector}

According to World Health Organization (WHO, 2013), the shortage in supply for healthcare 
labor is a common phenomenon at global level. However, this phenomenon is crucial in countries with worst healthcare performance indicators particularly Africa and Middle Eastern Countries including Jordan. WHO in its report during the third Global Forum on Human Resources for Health projected that by the end of 2035, the world will be short of 12.9 million healthcare workers in both developed and developing Nations. In 2006, World Health Report launched the Health Workforce Decade (2006-2015), with high priority given to retaining high-quality health care workers to mitigate this foreseen shortfall. The Kampala Declaration (2008) stressed the crucial role of retaining an effective, responsive and equitably distributed health workforce as a penance to sound human resources (HR) management practices needed for retaining effective health professionals in health care organizations (HCOs). Given the recruitment and retention reality of the health workforce in the twenty-first century, the role of HR managers in health care organizations (HCOs) and those who combine the role of HR managers with other responsibilities should not be underestimated (El-Jardali, Tchaghchagian, \& Jamal, 2009).

There are certain peculiarities common to several Low and Low-Middle Income countries, this has to do with supply of health professionals challenged by demographic trends; an aging population; growing shortages; limited education and training capacities; poor recruitment and retention strategies including out-migration of health professionals; skill-mix imbalance; misdistribution; poor HRH planning; absence of a reliable database; poorly informed policy decisions and slow health system reform (Ranson, Chopra, Atkins, Dal Poz, \& Bennett, 2010). The reality, however, is that rich and poor countries alike are desperately short of qualified health personnel and the situation is getting worse rather than better. Many countries have simply not foreseen this trend until it was too late (WHO, 2014). The worst case of the shortages of health workers globally is in the Eastern Mediterranean Region (Alameddine et al., 2012).

Willis-Shattuck, Bidwell, Thomas, Wyness, Blaauw, and Ditlopo (2008) conducted a study title: "Motivation and retention of health workers in developing countries: a systematic review". The authors concluded that key constraint to achieving the Millennium Development Goals (MDGs) is the absence of a properly trained and motivated workforce. Loss of clinical staff from low and middle-income countries is crippling already fragile health care systems. Health worker retention is critical for health system performance and a key problem is how best to motivate and retain health workers. After critical review of literature and some database, seven (7) core motivational themes were identified: financial rewards, career development, continuing education, hospital infrastructure, resource availability, hospital management and recognition/appreciation. There was some evidence to suggest that the use of initiatives to improve motivation had been effective in helping retention as shown in the chart below (Willis-Shattuck et al., 2008).

Figure 1 below confirmed that motivational factors are undoubtedly country specific (Willis-Shattuck et al., 2008). However, financial incentives, career development and management issues are core factors. Nevertheless, financial incentives alone are not enough to motivate health workers. It is clear that recognition is highly influential in health worker motivation and that adequate resources and appropriate infrastructure can improve morale 
significantly. Furthermore, adequate supplies and appropriate infrastructure are factors that can significantly improve morale.

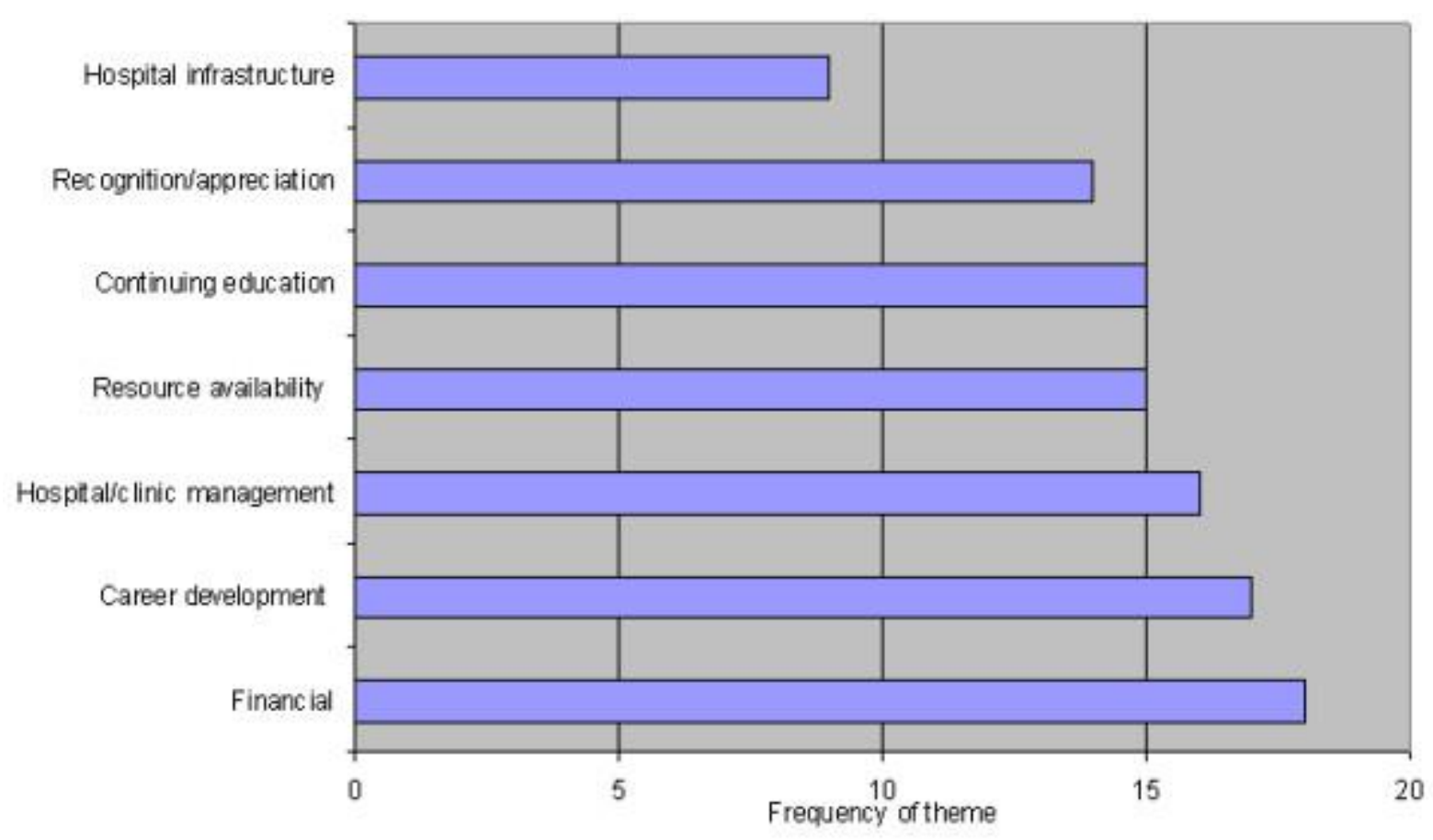

Figure 1. Name

\section{Jordan Employee Retention Experience in Health Sector}

Jordanian healthcare system is divided into governmental, military, university, and private hospitals. In the governmental sector, the Ministry of Health operates 31 hospitals, contributed $38 \%$ of all hospital beds; the Military Royal Medical Services run 12 hospitals, providing $24 \%$ of all beds; the Universities Hospitals contributed 3\% of total beds; and the Private Sector provides 35\% of all hospital beds (Al Hussani, Darawad, Saleh, \& Hayajneh, 2013). The governmental hospitals provide health services has a social responsibility to the society, the cost of the medical services being render by Jordanian Ministry of Health is almost free for citizen. According to Al Ghad Newspaper, the main problem of Jordanian Ministry of Health is the shortage of medical staff in government owned hospitals, the estimated shortage ranges from $30 \%$ to $40 \%$ with the possibility to increase if not arrested in earnest.

Jordanian experience has revealed interrelationship between leadership style and employee retention in health sector. For example, Mohammad, AL-Zeaud, and Batayneh (2011) found that transformational leadership style has a positive influence on job satisfaction of the medical staff working in private hospitals in the capital of Jordan (Amman) and reduce levels of distress. There is also a strong indication between HR practices of compensation, career development, work-life balance and employee engagement at Jordanian health sector. Daib 
(2015) in his research advocated aggressive pursue of HR practices to stall the looming mass exodus of Jordan doctors. The researcher believes that the specialist doctors suffer from unfairness in compensations, performance appraisal, and career opportunities etc., which lead to dissatisfaction, discontent, and lack of commitment thereby threatening their continuous stay in services of Jordan Ministry of Health (Diab, 2015). Some Jordanian medical staff left to work in Gulf countries because of higher salaries and better working conditions. Poor working conditions and an unsupportive work environment are two of the factors that drive medical staff a way to seek greener pasture in other countries (Abualrub, Omari, \& Al-Zaru, 2009).

The theoretical and empirical examination revealed that human resources practices factors that could affect employee retention are numerous and include compensation, career management and work-life balance. However previous studies on best practices in HRM have been fragmented and researchers have not arrived at an effective blend of practices that could improve organizational commitment and retention (Chew \& Chan, 2008). While previous studies focused on the relationship among the variables, this study is underpinned by the Herzberg two factors theory to justify the existence of correlation between HRM practices, leadership style and employee retention. Further, this study carefully considers the benefits and commitment of the relational parties as advocated by Blau (1964) social exchange theory (SET).

\section{Underpinning Theories}

According to Kerlinger (1979) a theory is a set of interrelated constructs or variables, definitions and propositions that presents a systematic view of a phenomenon by specifying relations among variables, with the purpose of explaining a natural phenomenon. Different reasons have been given why employees leave one organization for another. Chiboiwa, Samuel, and Chipunza (2010) assert that some of these reasons include recruitment practices, lack of competitive compensation system, management style, lack of recognition, poor working conditions, job insecurity, job dissatisfaction, lack of promotion and inadequate training and development opportunities. These reasons can be generally classified into intrinsic and extrinsic motivational factors. This study limits the scope to Herzberg two factor theories and social exchange theory.

\subsection{Herzberg Two Factor Theory}

When considering an effective strategy to retain employee in an organization, management must not rely only on intrinsic variables to influence employee retention; but rather combine both intrinsic and extrinsic variables. The dimensions of HR practices are directly or indirectly connected with satisfy/motivator and dissatisfy/hygiene advocated by Herzberg (1959). Herzberg's theory states that there are certain factors that are related to the content of the job and provides satisfying experiences for employees. These factors are called motivators or satisfiers and include achievement, recognition, the work itself, responsibility, advancement, and growth. The second aspect of the theory states that, there are non-job-related factors that can cause dissatisfying experiences for employees. These factors are known as hygiene factors or dissatisfiers and include company policies, salary, co-worker 
relations, and style of supervision (Steers \& Porter, 1991). However, removing the causes of dissatisfaction (through hygiene factors) would not result in a state of satisfaction; instead, it would result in a neutral state (Herzberg, 1959). As explained later in this study, HR practices of compensation, career development and work-life balance are grounded on either intrinsic or extrinsic or both.

\subsection{Social Exchange Theory (SET)}

The social exchange theory argues that all human connections are shaped by the use of subjective cost-benefit, which is rooted in three vital areas: economics, psychology and sociology (Homans, 1958; Blau, 1964). The theory explains social exchange as a process of negotiated exchanges between parties in which both parties involved in the exchange take responsibility for one another and strongly depend on each other. In addition, the interactions between parties are usually seen as mutually dependent and contingent on the actions made by the other persons (Blau, 1964). Emerson (1976) who studied social exchange theory in psychological was concerned on the individual behavior when interacting with one another, and suggested that power, conformity, status, leadership and justice within the social behavior are important in explaining the theory. Cropanzano and Mitchell (2007) discovered that social exchange relationship in a typical work setting determines the continuous retention or termination of contract from either party. The authors suggested that one employee can form distinguishable social exchange relationship either with his or her immediate supervisor, co-workers, organizations, customers, as well as the suppliers, where these distinct relationships have implications on their behavior. Thus, the above discussion on SET is that employees are likely to continue the relationship with their employer/manager/owner when they perceive that the relationship is worthwhile for them, and terminate the relationship when the costs are more than the rewards that they gain from the relationship. The focus of this theory as applied on this study is on the leadership style (transformational) in respect to employee retention.

\section{Literature Review}

This study conceptualized the relationship between HR practices dimensions (compensation, career development and work-life balance), leadership style (transformational) and employee retention from the perspectives of Jordan health sector.

\subsection{Employee Retention}

The main purpose of retention is to prevent competent employees from leaving an organization as this could have adverse effect on productivity and profitability (Samuel \& Chipunza, 2009). Retaining well motivated staff is vital to the success of an organization. Therefore, the challenge for most organizations today centered on how to formulate effective employee retention strategies that will enable organizations to retain employees they consider critical to the attainment of organizational goals (Chiboiwa, Samuel, \& Chipunza, 2010). Whiles retaining employees has several benefits, research has shown that turnover or losing critical employees is costly to organizations. Samuel and Chipunza (2009) contend that, when high performers leave an organization, productive talent and the capacity to gain competitive 
advantage is lost. In situations where the overall workload remains the same, the short-term burden on the remaining employees will increase and this is likely to have a negative effect on their motivation. In the long run, the organization-specific knowledge, skills, and know-how that long-time employees possess will be lost once they leave (Yamamoto, 2011). All these costs make employee retention an important issue for organizations to consider.

Mat Zin, Ahmad, Ngah, Ismail, Ibrahim, and Abdullah (2012), in their study, suggested that various strategies could be used for retention in Malaysia SMEs, including intrinsic and extrinsic factors of motivation, such as training and development, recognition, achievement, work and responsibility, company policy, supervision working conditions, interpersonal relations, job security and compensation. They also suggested that both intrinsic and extrinsic factors could be divided into three factors which include organizational strategies factors, organizational cultural and benefit factors to retain employees. Therefore, the intrinsic and extrinsic factors are vital in retaining employees in Malaysia. Sandhya and Kumar (2011) classified retention strategy into three stages, which as bottom stage, middle stage, and top stage. Retention strategy used for the bottom level is inclusive of performance appraisal, offering workplace conveniences, support by the employer, recognizing professionalism, providing compensatory monetary benefits, providing perks, recreation and fun at work, and occasional stress relievers. Meanwhile, middle level retention strategy consists of recognition, enhances personal growth and opportunities through offering training and development, providing workplace conveniences and safety measures, benefits program and support for family, as well as performance appraisal. The high level retention strategy is more on promoting and encouraging work/life effectiveness; considering employees' esteem needs, providing professional training and development, offering environment of trust and finally hiring the right people for the right job in the right place at the right time.

The connection between employee retention and the determinants are clearly stated in the theory particularly the Herzberg and social exchange theories. In the context of HR practices, this study identified compensation, career development and work-life balance. In relation to leadership style, this study was limited to transformational leadership common in collectivism culture like Arab Countries.

\subsection{Compensation}

Martochio (2013) viewed compensation as the intrinsic and extrinsic rewards that employee receive for performing their jobs. It is the desire of every employee that compensation system they received is fair and commensurate with their skills, experiences and knowledge (Long, Perumal \& Ajgbe, 2005). While Johari, Yean, Adnan, Yahya, and Ahmad, (2012) believed that compensation system helps to attract, retain and motivate employees to continue contributing towards organizations. Employee compensation includes all forms of payment and rewards received by employees for the performance of their jobs (Snell \& Bohlander, 2007). Direct compensation includes employee wages and salaries, incentive-payments, bonuses and commissions. Whiles indirect compensation comprises the many fringe benefits provided by employers and non-financial compensation including health care, life insurance, subsidized lunch, leave policy, overtime, pension plan and transportation policies. The link 
between employee retention and compensation is grounded on satisfier/motivator and dissatisfier/hygene factors canvassed by Herzberg.

According to Willis (2000), the most critical issue when it comes to attracting and retaining talents is direct compensation. Parker and Wright (2000) also assert that the cornerstone of the contractual and implied agreement between employees and employers is money which is assumed to influence behavior under several circumstances. As a result, some companies may even provide remuneration packages which are well above the market rate to attract and retain critical talents (Parker \& Wright, 2000). Extant literature revealed that money is the prime retention factor and many employees cite better pay or higher compensation as the reason for frequently changing job in recent times (Mathis \& Jackson, 2004). Khan (2010) argues that comprehensive compensation and rewards play an effective role in attracting the best candidates, shaping employee behavior and performance outcome, and facilitating retention of employees. Related studies also show that salary is one of the strategies in motivating the workers, in order to enhance their performance, commitment and satisfaction. Tella et al. (2007) supported the notion that compensation influence the workers' behavior as well as attract, and increase the intention to stay which often lead to the higher performance in the organization. Ramay (2011) also confirmed that pay satisfaction had a significant positive relationship with the organizational commitment. In a similar study by Munap et al. (2013), salary was one of the factors that can influence the probability of decision making for the workers to join, leave or stay in the organization. Therefore, employee decision is to a large extent tied to compensation (Salary and other benefits), in line with our theory, employee will stay if motivated, and quite when dissatisfied.

\subsection{Career Development}

In a knowledge economy, developing competencies forms an essential part of organization's competitiveness. Knowledgeable and highly skilled employees improve productivity, enhance quality of products and services, effect positive changes in processes and deliver quality service to customers (Khan, 2010). Most organizations may use career management programs to assist their employees to properly plan their careers because it is believed that, generally, employees react positively to career development and advancement opportunities. According to Andersson (2012), training \& development (R\&D) constitutes a local management discourse that may affect different levels of work identity, such as personal development, self-knowledge and personal growth. Bitner and Zeithmal (2004) conclude that expenditure on training leads to the competitive advantage of an organization. Nowadays, dynamic environments and changing customer needs require unique solutions and modern employee skills to provide superior services and products. It is therefore not surprising that in modern times, the emphasis on training and the acquisition of new skills are increasingly becoming the key for organizations to attain enduring outcomes.

Career management presents several immediate and longer term benefits such as obtaining higher salary, improving one's marketability, positioning oneself for future job opportunities and enhancing job satisfaction. Khan (2010) argues that training and development generate tangible outcomes such as improved productivity, quality products and services, and resource 
optimization as well as intangible outcomes such as enhanced self-esteem, high morale, and satisfaction of employees due to acquisition of additional knowledge, skills and abilities. Hence it has been suggested that organizations should pursue participative mechanism to develop career related objectives for employees, make effective plans, implement and monitor the effectiveness of these plans to achieve employees' career objectives. Formal or informal training increases learning outcomes significantly and changes an organization's performance (Clarke, 2004). Training is part of an organization's investment because there are higher returns to the organizations in terms of knowledge, skills (Finegold et al., 2005) and the quality of people working (Grobler \& Zock, 2010). Formal training is anchored on self-reflectivity, theories and concepts in action. Informal training on the other hand, is focused on work-based learning and workplace development by contrast, such as mentoring, coaching, job rotation, job shadowing, projects and assignments (Clarke, 2004). If the aim of training is to generate explicit and tacit knowledge to be transmitted within the organization, it is natural for employee to feel motivated and stay put on job if given necessary incentives, otherwise quite if stagnated for too long (Clarke, 2004). Herzberg two factors theory advocated the above scenario and thus recommended to be use in relation to employee retention and career development.

\subsection{Work-Life Balance}

The conflict between work and career on the one hand and private life on the other is currently assuming large proportions in our society. In the modern lifestyle, 24 hours per day is not enough to tackle work and personal tasks. Work-life balance has become a pre-dominant issue in the workplace especially in the society filled with conflicting responsibilities and commitments (Lockwood, 2003). Facilitating a good work-life balance is one of the retention factors frequently cited in the literature (Anderson et al., 2002). Work-Life Balance (WLB) is fast becoming an important work related issue and over the past decade, an increasing number of scholarly articles have been promoting its importance. The demands of work and family are not always compatible, leading to conflict between the two domains which may generate the potential for negative effects, including turnover (Mesmer-Magnus \& Viswesvaran, 2005). According to Deery (2008) it appears that the conflict between these important dimensions of human activity can cause both job dissatisfaction and family conflicts and hence intention to leave an organization synonymous to two factor theory advocated by Herzberg.

Withers (2001), assert that WLB programs cover a variety of interventions, and include such practices as dependent care leave, childcare subsidies, eldercare programs, counseling, referral and flexible working hours. While there is no ready-made definition of what constitutes a WLB practice, the term usually refers to one of the following: flexible work options, organizational support for dependent care and family or personal leave (Estes \& Michael, 2005). Some organization also implement specific programs to help employees balance their lives both at work and at home and these include flexible employment, family-friendly work policies, telecommuting, well-being programs, employment conditions and social and community practice (Beauregard \& Henry, 2009; Zatzick \& Iverson, 2006). Work-life balance policies help employees reduce the impact of work on family life, benefit 
of Work-life balance thereby often reducing stress level, while increasing focus and motivation at work knowing that family and work commitments are being met. For employers, these policies often mean greater staff loyalty and commitment, resulting in lower turnover, and higher attraction levels.

Work-life balance employment practices are concerned with providing scope for employees to balance what they do at work with the responsibilities and their interests outside work environment with the aim to reconcile the competing claims of work and home by meeting their own needs as well as those of their employers. A study by Maxwell (2005) also indicated that WLB policies such as the introduction of flexible working hours and arrangements, provision of better training, breaks from work and better work support do not only address WLB issues but also enhance employee retention. The synchronization between these HR practices and employee retention is a general representation of larger employer/employee relationship. However, the specialty in health sector makes the study scope interesting. Manpower retention in health sector especially the doctors proved to be fragile, ditto all human endeavors. To compound the situation, the ratio of a doctor to number of patients has being a tall dream for low and middle-income countries over the years (WHO, 2013).

\subsection{Transformational Leadership Style}

Nowadays, employees want to have leaders who pay attention to their needs for completion and growth, by acting as a mentor, and taking care of employees' needs over their own needs. Fitzgerald and Schutte (2010) stated that leaders, who are transformational, would motivate and inspire employees towards the vision, understand employees' needs, and help employees to reach their potential, all of which contribute the best outcomes for the organization. Transformational leadership is the relationship between leaders and followers that raise the value and motivation of the followers to higher levels. The followers of transformational leadership have a belief in their leaders and the organization's mission. This type of leadership should be encouraged in care giving sectors such as health. This will promote harmonious relationship between the patients and doctor/nurses. The top management relationship with the line staff usually has multiplier effects on their work, their relationship with colleagues, family and clients.

Transformational leadership comprises of the following five (5) factors according to Gilbert (2016), namely: (1) Idealized influence or attributed charisma- is how followers think of the leader resulting in how they perceive the leader's power, confidence, and transcendent ideals. (2) Idealized influence or behavior charisma - specific leader behavior about the leaders' values and beliefs, their sense of mission and purpose, as well as their ethical and moral orientation. (3) Inspirational motivation - refers to the leader's capability to inspire and motivate followers to reach ambitious goals, raise followers' expectations, communicate confidence, and create a self-fulfilling prophecy. (4) Intellectual stimulation- refers to the manners leaders question the status quo, appeal to the followers' intellect to make them question their assumptions and invite, and how to innovate and solve problems creatively. (5) Individualized consideration - this is about leaders who give customized socio-emotional 
support to followers, and develop and empower them simultaneously.

In summary, transformational leadership refers to the leader elevating followers beyond immediate self-interest. This is achieved through idealized influence, inspiration, intellectual stimulation and individualized consideration (Gilbert, 2016). It boosts the follower's maturity and ideals, and is also about the leader's achievement, self-actualization, well-being and the organization (Erkutlu, 2008). The benefits in this style of leadership is two ways: the top management get good commitment from line staff which in turn increase productivity, while the line staff enjoyed sense of belonging, recognition and growth at work (Ramachandran \& Krishan, 2009). The symbiotic relationship is the trust of social exchange theory (SET). Bass (1999) stated that followers who work with a transformational leader or transformational team take care of each other, stimulate each other intellectually, inspire each other, identify with the team goal and are highly productive. Ramachandran and Krishan (2009) concluded that employees in different cultures understand commitment and transformational leadership in different ways. In addition, transformational leadership is stronger in collectivistic cultures than in individualistic cultures. Most developing countries exhibit collectivism and thus promoting transformational leadership in Jordan for example will meet little or no resistance. In view of alarming brain drain phenomenon in Easter Mediterranean in core service concerns, this study highlighted SET to underpinned employee retention and other variables in health sector.

\section{Conceptual Relationship}

A conceptual relationship is referred to as a combination of interrelated concepts guiding the research, identifying the factors to be measured and shedding light on the relationships needed in the study (Borgatti, 1999). The schematic framework also guides the researcher's observations. This study conceptualized the relationship between human resources practices, leadership style, and employee retention.

The main constructs include employees' retention as a dependent variable and human resources practices, leadership style, as independent variables. Herzberg's two factor theory and social exchange theory were used to explain the relationship between all variables used in this study. Herzberg two factor theory guide this research framework by explicitly underpinning the benefits and otherwise on the employee's attitude towards their job. For instance, the leadership style could generate satisfaction and dissatisfaction which could affect job performance. Similarly, social exchange theory (SET) compliments Herzberg in terms of reciprocal relationship between the organization and employee. This ultimately led to employee retention to benefits the two parties. The research framework is conceptualized based on these theories. 
Independent variables

Dependent variablee

- Compensation

- Career Development

- Work life balance

- Transformational leadership style

Figure 1. Schematic framework

Many studies in the past have shown both conceptual and empirical relationship between human resource management such as compensation, career development, and work life balance. The results of most of these studies were positively related to employee retention in various settings and countries (Osemeke, 2012; Hong et al., 2012; Okeudo \& Cmilt, 2012; Omolo et al., 2013;; Amin, 2013; Akter, 2012; Bal et al., 2014 ; Kroon \& Freese, 2013). However, these studies relied on theories such as technology acceptance model (TAM), unified theory of acceptance and use of technology (UTAUT), theory of planned behavior (TPB) and theory of reason action (TR) (Imna \& Hassan, 2015; Morin et al., 2015; Sanjeevkumar, 2012). The focus of this study and theories make a difference from the previous ones.

Health care sector is human resource driven and required professional training, handling and relationship. The psychology attached to doctor attention to patient is of great value to the organization. Therefore, employee with good character will be cherished as asset to be retained long through application of Herzberg and social exchange theories (Hong et al., 2012). This will in turn benefit the organization and the employee simultaneously (Kroon \& Freese, 2013). While there was dearth of studies revealing these conceptualized relationship in health sector, the few available focused on nurses' retention (Wagner, 2006). This study is part of a larger study aimed at empirically testing the relationship between employee retention in health sector particularly doctors and HR practices (compensation, career development and work-life balance) and peculiar leadership style in Arab Countries. All the relationships between IVs and DV are proposed to be positive.

$\mathrm{H} 1$ : Compensation is positively related to employee retention.

$\mathrm{H} 2$ : Career development is positively related to employee retention.

H3: Work-Life Balance is positively related to employee retention.

H4: Transformational leadership style is positively related to employee retention

\section{Conclusion}

This study has presented theoretical arguments, debates, assumptions and inconclusive discussions on past and existing scholarly works in the areas of employee retention, human 
resources practices, and leadership style. The theoretical and empirical examination revealed that human resources practices factors that could affect employee retention are numerous and include compensation, career development, and work-life balance. However previous studies on best practices in HRM have been fragmented and researchers have not arrived at an effective blend of practices that could improve organizational commitment and retention (Chew \& Chan, 2008). While previous studies focused on the relationship among the variables, this study is underpinned by the Herzberg two factors theory and social exchange theory to justify the existence of correlation between HRM practices, leadership style and employee retention.

Studies that focused on the influence of human resources practices and leadership style (such as compensation, career management opportunity, work life balance, and transformational leadership) are still limited and inconclusive. Moreover, there appear to be disconnection between the variables used in most of the previous studies in terms of underpinning theory. This study carefully considers the benefits and commitment of the relational parties as advocated by Blua (1964) social exchange theory (SET) and supported the argument based on motivation and hygiene factors used by Herzberg (1959).

\section{References}

Abualrub, R. F., Omari, F. H., \& Al-Zaru, I. M. (2009). Support, satisfaction and retention among Jordanian nurses in private and public hospitals. International Nursing Review, 56(3), 326-332. https://doi.org/10.1111/j.1466-7657.2009.00718.x

Akter, S. (2012) Employee Satisfaction of SAINSBURY'S an Exploratory Study. International Journal of Academic Research in Business and Social Sciences, 2(8).

Al Hussani, M., Darawad, M., Saleh, A., \& Hayajneh, F. A. (2013). Predicting Nurses' Turnover Intentions by Demographic Characteristics, Perception of Health, Quality of Work, and Work Attitudes. 1st Annual International Interdisciplinary Conference, 5(1), 593-601. https://doi.org/10.5829/idosi.wjms.2014.11.1.8450

Alameddine, M., Saleh, S., El-Jardali, F., Dimassi, H., \& Mourad, Y. (2012). The retention of health human resources in primary healthcare centers in Lebanon: A national survey. BMC Health Services Research, 12(2), 1-11. https://doi.org/10.1186/1472-6963-12-419

Amin, A. (2013). The Impact of Employees Training On the Job Performance in Education Sector of Pakistan. Middle-East Journal of Scientific Research, 17(9), 1273-1278. https://doi.org/10.5829/idosi.mejsr.2013.17.09.12289

Anderson, S. E., Coffey, B. S., \& Byerly, R. T. (2002). Formal organizational initiatives and informal workplace practices: Links to work-family conflict and job-related outcomes. Journal of Management, 28(6), 787-810.

Andersson, T. (2012). Normative identity processes in manager's personal development training. Personnel Review, 41(5), 572-589. https://doi.org/10.1108/00483481211249111

Armstrong, M. A. (2010). Handbook of Human Resource Management Practice. London. 


\section{I Macrothink}

World Journal of Business and Management

ISSN 2377-4622

2017, Vol. 3, No. 1

Bal, Y., Bozkurt, S., \& Ertemsir, E. (2014). Determining the Influence of HRM Practices on Increasing Organizational Commitment: An Empirical Research from Turkey. In Human Capital without Borders: Knowledge and Learning for Quality of Life; Proceedings of the Management, Knowledge and Learning International Conference 2014, 1025-1033.

Bass, B. M. (1999). Two decades of research and development in transformational leadership. European Journal of Work and Organizational Psychology, 8(1), 9-32. https://doi.org/10.1080/135943299398410

Beauregard, T. A., \& Henry, L. C. (2009). Making the link between work-life balance practices and organizational performance. Human Resource Management Review, 19(1), 9-22. http://dx.doi.org/10.1016/j.hrmr.2008.09.001

Bitner, M. J., \& Zeithaml, V. A. (2004). Service marketing. New York: McGraw Hill

Blau, P. M. (1964). Exchange and power in social life. New York: John Wiley.

Borgatti, S. P., Everett, M. G., \& Freeman, L. C. (1999). UCINET 6.0 Version 1.00. Natick: Analytic Technologies.

Chew, J., \& Chan, C. A. C. (2008). Human resource practices, organizational commitment and intention to stay. International Journal of Manpower, 29(6), 503-522. https://doi.org/10.1108/01437720810904194

Chiboiwa, M. W., Samuel, M. O., \& Chipunza, C. (2010). An examination of employee retention strategy in a private organization in Zimbabwe. African Journal of Business Management, 4(10), 2103 -2109.

Clarke, N. (2004). HRD and the challenges of assessing learning in the workplace. International Journal of Training and Development, 8(2), 140-156. https://doi.org/10.1111/j.1468-2419.2004.00203.x

Cropanzano, R., \& Mitchell, M.S. (2007). Social exchange theory: an interdisciplinary review. Journal of Management, 31(6), 874-900. https://doi.org/10.1177/0149206305279602

Deery, M. (2008). Talent management, work-life balance and retention strategies. International Journal of Contemporary Hospitality Management, 20(7), 792-806. https://doi.org/10.1108/09596110810897619

Diab, S. M. (2015). The Role of Internal Environment in Jordanian Ministry of Health in Migration of Specialist Doctors. International Journal of Marketing Studies, 7(1), 190-198. https://doi.org/10.5539/ijms.v7n1p190

El-Jardali, F., Tchaghchagian, V., \& Jamal, D. (2009). Assessment of human resources management practices in Lebanese hospitals. Human Resources for Health, 7(1), 70-84. https://doi.org/10.1186/1478-4491-7-84

Emerson, R. M. (1976). Social exchange theory. Annual Review of Sociology, 2(1), 335-362 https://doi.org/10.1146/annurev.so.02.080176.002003 


\section{Al Macrothink}

World Journal of Business and Management

ISSN 2377-4622

2017, Vol. 3, No. 1

ErKutlu, H. (2008). The impact of transformational leadership on organizational and leadership effectiveness. Journal of Management Development, 27(7), 708-726. https://doi.org/10.1108/02621710810883616

Estes, S. B., \& Michael, J. (2005). Work-family policies and gender inequality at work: A Sloan Work and Family Encyclopedia entry.

Finegold, D., Lavenson, A., \& Van Buren, M. (2005). Access to training and its impact on temporary workers. Human Resource Journal, 15(2), 66-85. https://doi.org/10.1111/j.1748-8583.2005.tb00147.x

Fitzgerald. S., \& Schutte. N. S. (2010). increasing transformational leadership through enhancing self-efficacy. Journal of Management Development, 29(5), 495-505. https://doi.org/10.1108/02621711011039240

Gilbert, S., Horsman, P., \& Kelloway, E. K. (2016). The Motivation for Transformational Leadership Scale: An examination of the factor structure and initial tests. Leadership \& Organization Development Journal, 37(2), 158-180. https://doi.org/10.1108/LODJ-05-2014-0086

Grobler, A., \& Zock, A. (2010). Supporting long-term workforce planning with a dynamic aging chain model; a case study from the service industry. Human Resource Management, 49(5), 829-848. https://doi.org/10.1002/hrm.20382

Herzberg, G., \& Howe, L. L. (1959). The Lyman bands of molecular hydrogen. Canadian Journal of Physics, 37(5), 636-659. https://doi.org/10.1139/p59-070

Homans, G. C. (1958). Social behavior as exchange. American Journal of Sociology, 63(1), 597-606. https://doi.org/10.1086/222355

Hong, E. N. C., Hao, L. Z., Kumar, R., Ramendran, C., \& Kadiresan, V. (2012). An effectiveness of human resource management practices on employee retention in institute of higher learning: A regression analysis. International Journal of Business Research and Management, 3(2), 60-79.

Imna, M., \& Hassan, Z. (2015). Influence of Human Resource Management practices on Employee Retention in Maldives Retail Industry. International Journal of Accounting Business and Management (IJABM), 1(1), 1-28.

Johari, J., Yean, T. F., Adnan, Z., Yahya, K. K., \& Ahmad, M. N. (2012). Promoting employee intention to stay: Do human resource management practices matter? International Journal of Economics and Management, 6(2), 396-416.

Kerlinger, F. N. (1979). Behavioral research: A conceptual approach. New York: Holt, Rinehart and Winston.

Khan, M. A. (2010). Effects of human resource management practices on organizational performance - An empirical study of oil and gas industry in Pakistan. European Journal of Economics, Finance and Administrative Sciences, 24(2), 158-175. 
Kroon, B., \& Freese, C. (2013). Can HR practices retain flex workers with their agency? International Journal of Manpower, 34(3), 899-917. https://doi.org/10.1108/IJM-07-2013-0169

Kwenin, D. O. (2013) Relationship between work environment, career development opportunities and employee retention in Vodafone Ghana Limited. Global Journal of Human Resource Management, 1(4), 1-9.

Lockwood, N. (2003). Work/life balance: Challenges and solutions. Society for Human Resource Management.

Long, C. S., \& Thean, L. Y. (2011). Relationship between leadership style, job satisfaction and employees' turnover intention: A literature review. Research Journal of Business Management, 5(3), 91-100. https://doi.org/10.3923/rjbm.2011.91.100

Martocchio, J. J. (2013). Strategic Compensation: A human resource management approach. (7th ed.). Pearson Education Inc., United States of America

Mat Zin, S., Ahmad, N., Ngah, N. E., Ismail, R., Ibrahim, N., \& Tan Bin Abdullah, I. H. (2012). Motivation Model for Employee Retention: Applicability to HRM Practices in Malaysian SME Sector. Canadian Social Science, 8(5), 8-12. http://dx.doi.org/10.3968/j.css.1923669720120805.2239.

Mathis, R. L., \& Jackson, J. H. (2004). Human Resource Management (11th ed.). Singapore: Thomson Asia Pte. Ltd.

Maxwell, G. (2005). Checks and balances: the role of managers in work-life balance policies and practices. Journal of Retailing and Consumer Services, 12(3), 179-189. https://doi.org/10.1016/j.jretconser.2004.06.002

Mensah, R. D. (2014). Effects of Human Resource Management Practices on Retention of Employees in the Banking Industry in Accra, Ghana (Doctoral dissertation, KENYATTA UNIVERSITY).

Mesmer-Magnus, J. R., \& Viswesvaran, C. (2005). Convergence between measures of work-to-family and family-to-work conflict: A meta-analytic examination. Journal of Vocational Behavior, 67(2), 215-232. https://doi.org/10.1016/j.jvb.2004.05.004

Mohammad, S. I. S., AL-Zeaud, H. A., \& Batayneh, A. M. E. (2011). The relationship between transformational leadership and employees' satisfaction at Jordanian private hospitals. Business and Economic Horizons BEH, 5(2), 35-46. https://doi.org/10.15208/beh.2011.13

Munap, R., Mohd, B. M. I., \& Abdul, R. B. (2013). Organizational reward System and workers' satisfaction at Telekom Malaysia Berhad. Journal of Educational and Social Research, 3(3), 81-288.

Okeudo, D. G. N., \& Cmilt. (2012). The Impact of Human Resources Management in Logistic Service Providers and Supply Chain Capabilities: A Case Study. British Journal of 
Science, 4(1), 1-15.

Omolo, J. W., Oginda, D. M. N., \& Otengah, D. W. A. (2013). Influence of Human Resource Management Practices on the Performance of Small and Medium Enterprises in Kisumu Municipality, Kenya. International Journal of Business and Social Science, 1(4), 1-7.

Osemeke, M. (2012). The Impact of Human Resource Management Practices on Organizational Performance: A Study of Guinness Nigeria Plc. An International Journal of Arts and Humanities, 1(1), 79-94.

Parker, O., \& Wright, L. (2000). Pay and employee commitment: The missing link. Ivey Business Journal, 65(3), 70-79.

Ramachandran, S., \& Krishnan, V. R. (2009). Effect of transformational leadership on followers' and normative commitment: Culture as moderator. Journal of Great Lakes Herald, 3(1), 23-38.

Ramay, I. M. (2012). Antecedents of organizational commitment of banking sector employees in Pakistan. Serbian Journal of Management, 7(1), 89-102. https://doi.org/10.5937/sjm1201089A

Ranson, M. K., Chopra, M., Atkins, S., Dal Poz, M. R., \& Bennett, S. (2010). Priorities for research into human resources for health in low- and middle-income countries. Bulletin of the World Health Organization, 88(6), 435-443. https://doi.org/10.2471/BLT.09.066290

Samuel, M. O., \& Chipunza, C. (2009). Employee retention \& turnover: Using motivational variables as a panacea. African Journal of Business Management, 3(8), 410-415.

Sandhya, K., \& Kumar, D. P. (2011). Employee retention by motivation. Indian Journal of Science and Technology, 4(12), 1778-1782.

Sanjeevkumar, V., \& Wei, W. (2012). A case study on determinants of human resource practices influencing retention of employees in Kedah State Development Corporation, Malaysia. International Journal of Business and Social Research (IJBSR), 2(2), 42-53.

Slattery, J. P., \& Selvarajan, T. R. (2005). Antecedents to temporary employee's turnover intention. Journal of Leadership \& Organizational Studies, 12(1), 53-66. https://doi.org/10.1177/107179190501200106

Snell, S., \&. Bohlander, G. (2007). Training and development: Managing human resources (14th ed.). Manson, Ohio: South-Western

Steers, R. M., \& Porter, W. L. (1991). Motivation and work behavior (5th ed.). New York: McGraw-Hill Inc.

Stewart, G. L., \& Brown, K. G. (2009). Human Resource Management: Linking Strategy to Practices (2nd ed.). John Wiley \& Sons Inc. USA.

Tanwar, K., \& Prasad, A. (2016). Exploring the Relationship between Employer Branding and Employee Retention. Global Business Review, 17(3), 186-206. 
https://doi.org/10.1177/0972150916631214

Tella, A., Ayeni, C. O., \& Popoola, S. O. (2007). Work motivation, job satisfaction, and organizational commitment of library personnel in academic and research libraries in Oyo State, Nigeria. Library Philosophy and Practice (E-Journal), 118.

Thrush, A., (2012). Leadership in Higher Education. International Journal of Human Humanities and Social Sciences, 2(13), 1-12.

Wagner, S. E. (2006). Staff retention: from "satisfied" to "engaged". Nursing Management, 37(3), 24-29. https://doi.org/10.1097/00006247-200603000-00007

Wilkin, T., \& Nwoke, G. I. (2011). Career and Technical Education Teacher Shortage: A Successful Model for Recruitment and Retention. Journal of Stem Teacher Education, 48(1), 22-35.

Willis, C. (2000). Go for your goals. Working Women, 6-7.

Willis-Shattuk, P., Bidwell, P., Thomas, S., Wyness, L., Blaauw, D., \& Ditlopo, P. (2008) Motivation and retention of health workers in developing countries: A systematic review. BioMed Center (BMC) Health Services Research, 8, 247. https://doi.org/10.1186/1472-6963-8-247

Withers, P. (2001). Retention strategies that respond to worker values. Workforce, 80, 37-44.

World Health Organization. (2008). The Kampala declaration and agenda for global action.

World Health Organization. (2013). Global health workforce shortage to reach 12.9 million in coming decades.

Yamamoto, H. (2011). The relationship between employee benefit management and employee retention. The International Journal of Human Resource Management, 22(17), 3550-3564. https://doi.org/10.1080/09585192.2011.560871

Zatzick, C. D., \& Iverson, R. D. (2006). High-involvement management and workforce reduction: Competitive advantage or disadvantage? Academy of Management Journal, 49(5), 999-1015. https://doi.org/10.5465/AMJ.2006.22798180

\section{Copyright Disclaimer}

Copyright for this article is retained by the author(s), with first publication rights granted to the journal.

This is an open-access article distributed under the terms and conditions of the Creative Commons Attribution license (http://creativecommons.org/licenses/by/3.0/). 